\title{
Simulation of water turbine integrated with electrical generator
}

\author{
Dariusz Borkowski ${ }^{1, *}$, Michał Węgiel ${ }^{1}$, Paweł Ocłoń ${ }^{1}$, and Tomasz Węgiel ${ }^{1}$ \\ ${ }^{1}$ Cracow University of Technology, Warszawska St. 24, 31-155 Cracow, Poland
}

\begin{abstract}
The paper presents the analysis of the small hydropower plant working at variable speed. The hydro-set that consists of the guide vanes and propeller turbine integrated with the permanent magnet synchronous generator is simulated by using Computational Fluid Dynamics (CFD) in Ansys Fluent v18.0. The k- $\varepsilon$ and k- $\omega$ SST models, as well as the one-equation Spalart-Allmaras (SA) model, were tested. The comparison showed the significant divergence of the calculation results. The turbulence model selection influences the average value of the power and also the speed for which the power is maximal.
\end{abstract}

\section{Introduction}

Small Hydropower Plants (SHPs) are objects up to 10MW. The SHPs are mainly the run-of-the-river schemes, where the water storage is limited or impossible. Therefore, the operating parameters are influenced by the actual hydrological conditions. In order to improve the object profitability, the operating range of the turbine discharge needs to be maximal and the average efficiency of the energy conversion have to be possible high [1]. The standard turbine solutions implementing double regulation (e.g. Kaplan turbine) are relatively expensive and can be replaced by the simple propeller turbine working at variable speed [2]. The variable speed operation is provided by the power electronic converter (PEC) that matches electrical energy of the generator with power system requirements [3]. In order to improve the overall system efficiency, the permanent magnet synchronous generator (PMSG) can be used. The PMSG allows to eliminate the mechanical transmission gear by construction with high pair pole numbers, what decreases the generator nominal speed. Furthermore, the simple propeller turbine and flexible generator construction allows to integrate these two elements into one unit, what simplify the hydro-set construction [4].

The hydro-set containing propeller turbine integrated with electrical generator is not well investigated yet. In order to support the design process and determine the operating conditions the detailed modeling is required. The computational fluid dynamics (CFD) technique seems to be the most suitable taking into account qualitive and quantitive results and analysis of the fluid flow machines of complex geometries [5]. However, it requires a properly defined calculation model, which includes: precise geometry, proper grid generation, suitable turbulence model and correct boundary conditions [6].

The paper presents the CFD analysis using three turbulence models. First is the k- $\varepsilon$ realizable model providing good performance for flows with rotation and adverse pressure gradients influencing the boundary layers $[7,8]$. The second analyzed model is k- $\omega$ SST (Shear-Stress Transport), which combines standard k- $\omega$ model near the wall and $\mathrm{k}-\varepsilon$ model in the outer portion of the boundary layer. It gives the accurate results for flows with adverse gradient pressure (flows with separation), therefore it is reliable for turbines $[9,10]$. Finally, the one-equation Spalart-Allmaras turbulent model is applied. This is a robust model suitable for mildly complex flow under pressure gradient (airfoils, wings). By applying the Wall Treatment technique, it is also applicable in fluid flow machines with low grid resolution of boundary layer [11]. The hydro-set model is prepared and analyzed in Ansys Fluent v18.0 [12].

\section{Numerical modelling}

\subsection{Geometry description}

The analyzed scheme is the run-of-the-river SHP, which is situated in a bypass of the overfall weir. The crosssection of the SHP is presented in fig. 1. The SHP contains an axial-flow propeller turbine integrated with the permanent magnet synchronous generator (PMSG) [13]. The turbine is located in the generator rotor. The permanents magnets are mounted outside the rotor ring. The hydro-set contains also the guide vanes that controls the water volume flowing through the turbine (fig. 2). The fundamental and operating parameters of the modelled turbine are given in Table 1 [14].

\footnotetext{
* Corresponding author: dborkowski@pk.edu.pl
} 


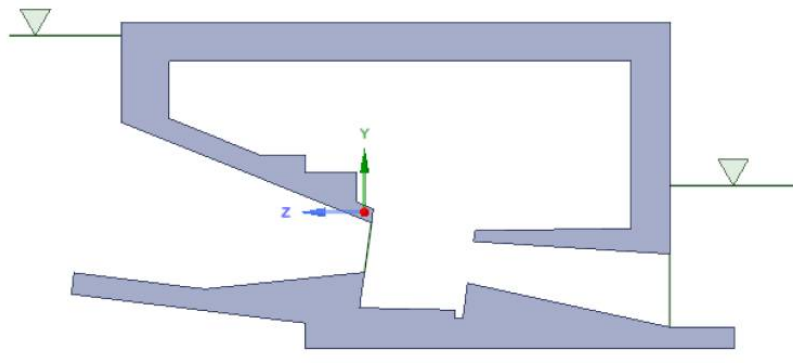

Fig. 1. SHP cross-section.

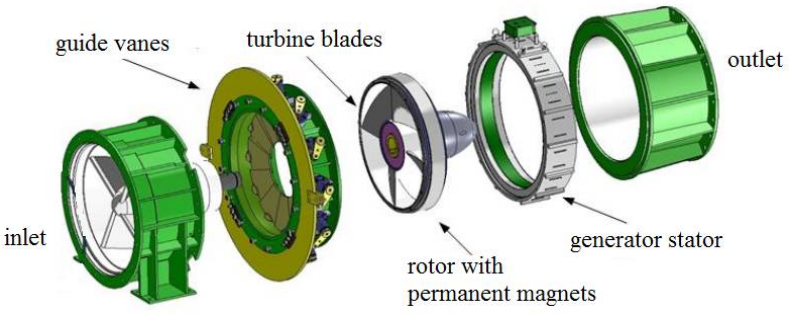

Fig. 2. Main elements of hydro-set.

Table 1. Setting Word's margins.

\begin{tabular}{|c|c|}
\hline Parameter (Unit) & Value \\
\hline Net head (m) & 2.75 \\
\hline Discharge (m3/s) & 3 \\
\hline Rotational speed (rpm) & 300 \\
\hline Output power (kW) & 75 \\
\hline Runner diameter (m) & 0.95 \\
\hline Number of runner blades & 4 \\
\hline Number of guide vanes & 12 \\
\hline
\end{tabular}

\subsection{Mesh grid generation}

The computational mesh was prepared in ANYS Meshing application based on the CAD model (Fig. 3.) for non-conformal components: the inlet pipe, hydroset tube that includes the guide vanes and the draft tube. The components were selected considering structure details in order to optimize the mesh. Additionally, to eliminate the computational complexity of the remeshing function the turbine rotor was prepared as a separate component. The curvature size function with a curvature normal angle equals $20^{\circ}$ and maximal mesh element of $30 \mathrm{~mm}$ was applied. Additionally, due to the significant geometry complexity of the guide vanes and rotor the element size was reduced to $20 \mathrm{~mm}$. The resulted mesh model is presented in Fig. 4.

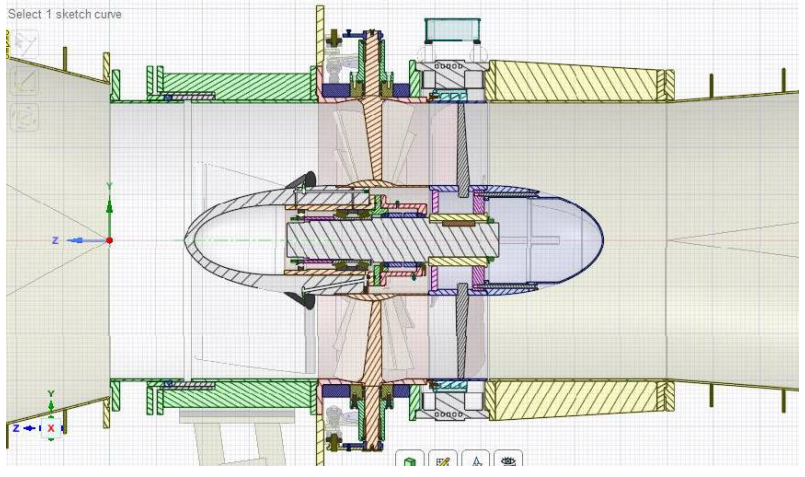

Fig. 3. SHP cross-section.

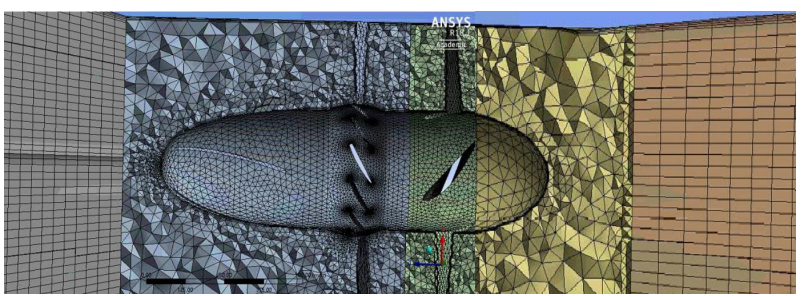

Fig. 4. SHP cross-section.

The generated mesh consists of about 1.2 million elements. The mesh quality was assessed using orthogonal quality and skewness parameters. The average value of the orthogonal quality equals 0,745 while the average skewness is 0,266 . Both parameters satisfy the recommended values (orthogonal quality $>$ 0.005 , skewness $<0.98$ ) for fluid flow calculations [1].

The calculations were performed for the three different models: Spalart-Allmaras, k- $\varepsilon$ realizable and k$\omega$ SST. The model convergence was assessed by the residuals, which measure the discretized equation solution inaccuracy [15]. The obtained residual curves show that the solutions of all models are converging to the exact solution after 50-100 iterations. The fastest stabilization provides the Spalart-Allmaras model, however some variations are presented in the obtained results.

\subsection{Boundary conditions and solver settings}

At the location of the inlet boundary condition the total pressure $(152600 \mathrm{~Pa})$ is given, which is the sum of the static pressure and dynamic pressure. The static pressure $(149885 \mathrm{~Pa})$ is defined by the hydrostatic head at the inlet $(4,95 \mathrm{~m})$, while the dynamic pressure $(2715 \mathrm{~Pa})$ results from the velocity of the fluid at the inlet $(2,33$ $\mathrm{m} / \mathrm{s}$ ). At the outlet boundary the backflow pressure $(125360 \mathrm{~Pa})$ caused by the hydrostatic head at the outlet $(2,45 \mathrm{~m})$, is specified (Fig. 5).

The pressure based solver allows to perform calculations of the fluid flow problems using separate or split equations. In case of the transient fluid flow, complex mesh grid or large time steps, the more accurate results are obtained by using the coupled algorithm. The most important solver parameters are listed in Table 2. 


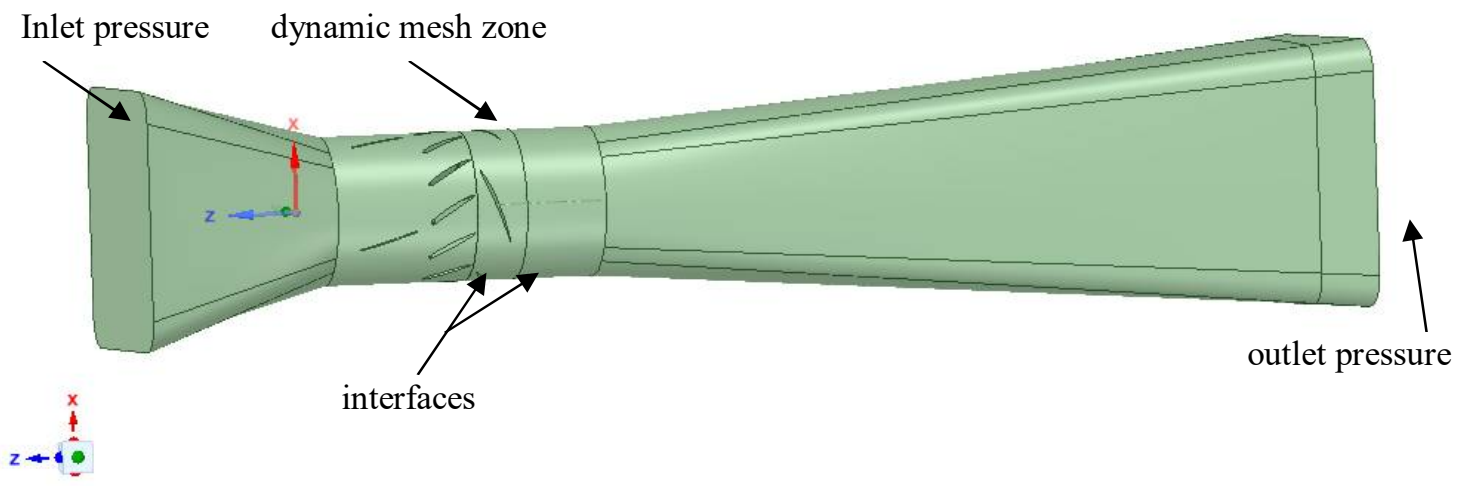

Fig. 5. Boundary conditions scheme.

Table 2. Solver settings and model relaxation factors.

\begin{tabular}{|c|c|}
\hline Solver Parameter & Value \\
\hline Pressure-Velocity Coupling & Coupled \\
\hline Discretization of Gradient & $\begin{array}{c}\text { Least Squares } \\
\text { Cell Based }\end{array}$ \\
\hline Discretization of Pressure & Presto \\
\hline $\begin{array}{c}\text { Discretization of Momentum } \\
\text { Discretization of Turbulent } \\
\text { Viscosity }\end{array}$ & $\begin{array}{c}\text { Second order } \\
\text { Upwind }\end{array}$ \\
\hline $\begin{array}{c}\text { Sransient Formulation } \\
\text { Upwind }\end{array}$ \\
\hline $\begin{array}{c}\text { Flow Courant number } \\
\text { Second Order } \\
\text { Implicit }\end{array}$ \\
\hline $\begin{array}{c}\text { Momentum and Pressure Explicit } \\
\text { Relaxation Factor }\end{array}$ & 100 \\
\hline $\begin{array}{c}\text { Density and Body Forces Under- } \\
\text { Relaxation Factors }\end{array}$ \\
\hline
\end{tabular}

\section{Results and discussion}

The calculation results of the CFD model for the three turbulence models are presented in Figure 6 in the form of power as function of turbine speed. Two values of the guide vanes angles are analyzed: $30^{\circ}$ and $60^{\circ}$, where $0^{\circ}$ corresponds to the close guide vanes.

Presented curves indicate the significant divergence of the calculation results. The turbulence model selection influences the average value of the power and also the speed for which the power is maximal.

The axial velocity distribution of hydro-set for both guide vane angles $\left(30^{\circ}\right.$ and $\left.60^{\circ}\right)$ are presented (Fig. 7). It can be seen that velocity increases with the guide vane angle increase, which is due to increases in discharge. It is seen that the flow is smooth for nominal guide vane angle $\left(60^{\circ}\right)$, whereas there is significant velocity gradient at guide vanes for lower angle $\left(30^{\circ}\right)$.

\footnotetext{
* Corresponding author: dborkowski@pk.edu.p
}

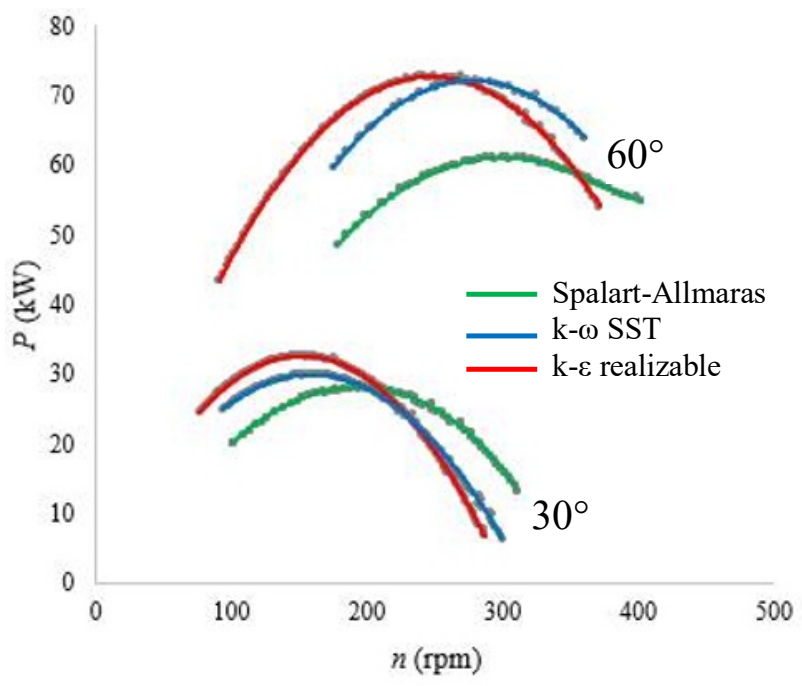

Fig. 6. Power as a function of turbine speed.

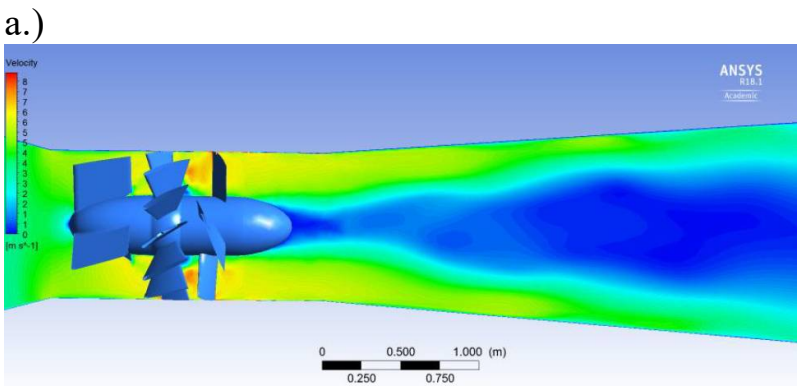

b.)

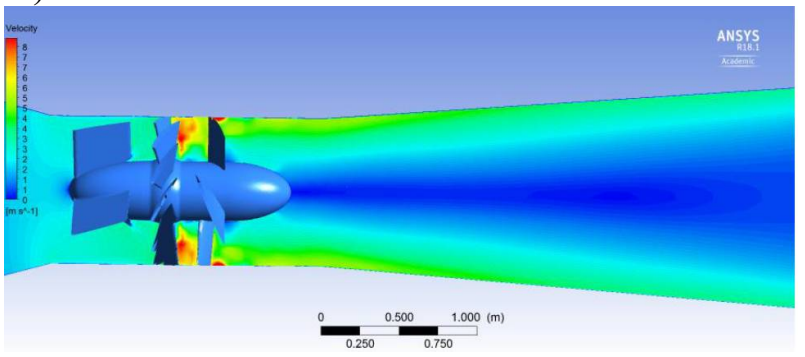

Fig. 7. Distribution of the axial velocity in the hydro-set for $60^{\circ}$ (a.) and $30^{\circ}$ (b.) of the guide vane angle. 


\section{Conclusions}

This paper determines the mechanical characteristics of a propeller turbine integrated with an electrical generator, operating at a variable rotational speed in a small hydropower plant, using the ANSYS Fluent software. For this purpose, a geometric model of the fluid domain was prepared. The numerical mesh was created that met the requirements of flow problems, and then using the available models of turbulence and calculation methods the characteristics are determined. The k- $\varepsilon$ and k- $\omega$ SST models, as well as the and one-equation SpalartAllmaras (SA) model, were tested. The SA model is preferred in the fluid flow calculations of flow machinery when the boundary layer mesh resolution is low. An additional advantage of using SA model is the shortened calculation time, which is especially crucial for variable time-dependent flows and large mesh models.

The simulations proved that the modeling methodology in the ANSYS FLUENT software can be successfully used in the process of designing and optimizing rotating machines, and in particular the facilities for which the prototyping is done. This mainly applies to prototype objects, to which practically every new hydropower plant can be calculated. At the stage of turbine design due to high acceleration resulting from the application of numerical methods, it is possible to analyze much more design variants at the same time and select the best option. Simultaneously, such a solution also brings financial benefits because in the numerical analysis only the computer model is changed and optimized, so there is no need to produce expensive prototypes every time the model changes.

\section{References}

1. G. A. Aggidis, E. Luchinskaya, R. Rothschild, D. C. Howard, Renewable Energy, 35, pp. 2632-2638 (2010)

2. G. Ardizzon, G. Cavazzini, G. Pavesi, Renew. Sustain. Energy Rev., 31, pp. 746-761 (2014)

3. J. Fraile-Ardanuy, J. R. Wilhelmi, J. J. Fraile-Mora, J. I. Pérez, IEEE Trans. Energy Convers., 21, pp. 569-574 (2006)

4. D. Borkowski, T. Wegiel, IEEE Trans. Energy Convers., 28, pp. 452-459 (2013)

5. J. H. Ferziger, M. Peric, Computational Methods for Fluid Dynamics, Springer Verlag, Heidelberg (2002)

6. C. Hirsch, Numerical Computation of Internal and External Flows: The Fundamentals of Computational Fluid Dynamics, 2nd Edition, Butterworth-Heinemann (2007)

7. T. C. Vu, M. Koller, M. Gauthier, C. Deschênes, , 25th IAHR Symposium on Hydraulic Machinery and Systems, Timisoara, Romania (2010)

8. A. Lipej, C. Poloni, Journal of Hydraulic Research, 38, pp. 73-79 (2000)
9. F. R. Menter, AIAA Journal, 32, pp. 1598-1605 (1994)

10. V. Prasad, K. S. Sayann, P. Krishnamachar, Indian Journal of Engineering \& Material Sciences. 16, pp. 229-236 (2009)

11. M. Kaniecki, Z. Krzemianowski, M. Banaszek, Transactions of The Institute of Fluid-Flow Machinery. 123, pp. 71-84 (2011)

12. ANSYS Inc., ANSYS Fluent Theory Guide, Canonsburg, (PA: release 18.0, 2016)

13. D. Borkowski, IEEE Transactions on Energy Conversion, 32, pp. 1090-1098 (2017)

14. T. Węgiel, D. Borkowski, D. Liszka, International Conference on the Sustainable Energy and Environment Development (SEED) (2016) doi: $10.1051 / \mathrm{e} 3$ sconf/20161000100

15. H. H. Peng, W. Qiu, S. Ni, Ocean Engineerings, pp. 304-317 (2013) 